\title{
JIMMBA
}

Jurnal Ilmiah Mahasiswa Manajemen, Bisnis dan Akuntansi

Homepage: http://journal.stieputrabangsa.ac.id/index.php/jimmba/index

\section{Pengaruh Keahlian Auditor dan Independensi Terhadap Audit Judgment}

\author{
Elizabeth Sihombing1, Valentine Siagian ${ }^{2}$ \\ 1,2 Universitas Advent Indonesia \\ Email: sihombingelizabeth007@gmail.com¹, valentine@unai.edu²
}

\begin{tabular}{|c|c|}
\hline ARTICLE INFO & ABSTRACT \\
\hline $\begin{array}{l}\text { Article History: } \\
\text { Received: September } 24^{\text {st }} \\
2020 \\
\text { Accepted: October } 16^{\text {st }} 2020 \\
\text { Published: October } 21^{\text {st }} 2020\end{array}$ & $\begin{array}{l}\text { This study aims to empirically test whether the auditor's expertise } \\
\text { and auditor independence affect audit judgment. The selected } \\
\text { sample is fifty respondents with technical purposive sampling. We } \\
\text { use a quantitative method, where data is obtained from auditors who } \\
\text { work in public accounting firms in Jakarta. We use multiple linear } \\
\text { regression analysis techniques with the SPSS program. We find that } \\
\text { partially, either expertise of auditors and auditor independence has } \\
\text { a positive and significant effect on audit judgment. F test has shown } \\
\text { that simultaneously auditor expertise and auditor independence } \\
\text { have a positive and significant effect on audit judgment. }\end{array}$ \\
\hline
\end{tabular}

\section{Pendahuluan}

Audit judgment merupakan kebutuhan auditor untuk mengaudit laporan keuangan perusahaan dan mengembangkan bukti yang diperoleh secara jelas berdasarkan kemampuan yang dimiliki oleh auditor, untuk menghasilkan ketepatan kualitas opini audit yang dikeluarkan oleh auditor (Komalasari dan Hernawati, 2015). Laporan keuangan memiliki empat karakteristik yang bermanfaat bagi pengguna yaitu mudah dipahami, sebanding, relevan, dan dapat diandalkan (SAK, 2002). Karakteristik tersebut digunakan oleh auditor untuk menyatakan laporan keuangan hasil audit dan oleh karena itu audit judgment juga menentukan kualitas audit. Dalam Paragraf 1 SA705 disebutkan bahwa terdapat aturan tentang tanggung jawab auditor ketika membuat laporan ketika merumuskan modifikasi opini yang disimpulkan atas laporan keuangan seperlunya, berdasarkan SA700.

Kualitas audit judgment akan membuktikan kualitas auditor dalam pengelolaan pekerjaannya (Pektra dan Kurnia, 2015), demikian pula penyusunan laporan keuangan di pemerintahan memerlukan kualitas audit yang baik terutama pada audit sektor publik juga menghindari pelanggaran dalam pengelolaan anggaran guna meningkatkan good governance (Nurfadillah, Nurhuda 2020). Masyarakat akan semakin mempercayai kualitas audit dari suatu kantor akuntan publik jika kualitas tersebut ditingkatkan melalui pekerjaan audit yang dilakukan oleh anggotanya (Mulyadi, 2013: 56), namun persepsi seorang auditor dalam menangani semua informasi yang terkait dengan tanggung jawab auditor dalam menangani 
risiko audit akan menghasilkan penilaian yang tidak akurat (Pertiwi, et al 2015), Dalam hal prosedur untuk mengungkapkan pendapat atas penilaian, auditor dapat mencocokkannya sesuai dengan kejadian masa lalu, sekarang, dan masa depan (Hasanah dan Rosini, 2016). Penilaian yang akurat akan membangun opini dan pengaruh yang baik secara tidak langsung dalam pengambilan keputusan yang tepat (Haryanto 2012). Kualitas audit yang baik akan semakin meningkatkan kepercayaan setiap pengguna atas laporan keuangan yang dihasilkan (Munawaroh. S 2019). Berdasarkan literatur sebelumnya, dapat disimpulkan bahwa audit judgment merupakan alat ukur yang digunakan oleh auditor sebagai bahan pertimbangan untuk menyimpulkan suatu laporan yang menghasilkan keputusan auditor atas penyajian laporan keuangan suatu entitas sesuai dengan keadaan dan fakta yang sebenarnya.

Tingkat efisiensi opini auditor yang telah mengikuti karakteristik Standar Profesional Akuntan Publik (SPAP) yang berlaku dan bukti yang didukung secara kompeten sesuai dengan Standar Profesional Akuntan Publik. Menilai pentingnya setiap keputusan yang diambil oleh auditor, seharusnya auditor telah menguasai pengetahuan tentang audit dan keahlian di bidang akuntansi untuk membuktikan bahwa pendapat dan keputusan yang diambil oleh auditor dapat membantu meningkatkan kinerja perusahaan dan menyelesaikan semua masalah dalam menganalisis kegiatan audit. laporan keuangan. Audit judgement dilakukan dengan prosedur penyelidikan laporan keuangan dalam proses waktu yang singkat dan tetap menghasilkan penilaian yang akurat (Hesdyana 2019). Faktor-faktor yang mempengaruhi seorang auditor dalam membuat suatu audit judgment perlu diketahui, karena hal tersebut menunjukkan kebijakan auditor dalam menyikapi informasi yang menghasilkan tanggung jawab dan hasil pertimbangan yang dibuatnya. Banyak faktor yang mempengaruhi audit judgment, beberapa di antaranya bersifat teknis dan non-teknis. Faktor teknis dilihat dari keterbatasan ruang lingkup dan waktu audit, sedangkan faktor non teknis yaitu aspek perilaku seperti pengaruh keterampilan auditor (Angel, Gracea, dkk 2017), independensi (Komalasari dan Hernawati, 2015), kompleksitas tugas (Putra dan Rani, 2016) dan locus of control (Azizah, Kustono, et al, 2019).

Dalam penelitian ini, penulis ingin mempelajari keahlian auditor dan independensi auditor sebagai faktor yang dapat mempengaruhi audit judgment. Penelitian terdahulu menyebutkan bahwa keahlian auditor mempengaruhi audit judgement yang dihasilkan karena auditor secara langsung merencanakan bahkan dalam penyusunan laporan keuangan (Artha, Herawati dan Darmawan, 2014). Dalam melakukan audit, keahlian auditor akan menunjukkan pengetahuan dan kemampuannya. Semakin luas keahlian yang dimiliki oleh auditor maka akan semakin mampu menghadapi permasalahan yang lebih dalam (Andrayani, Pituringsih, dkk 2019). Pendidikan formal dan pelatihan praktis tentang pengalaman audit sangat penting untuk meningkatkan keahlian seorang auditor. (Noor, Pujianth, \& Hamun, 2019).

Kemandirian menjadi karakter utama yang harus dimiliki oleh seorang auditor agar mampu menghadapi tekanan yang didapatkan baik dari atasan atasan maupun klien (Sitanggang, 2020). Auditor dengan independensi yang baik akan mendukung pelaksanaan kewajiban dan pekerjaan yang baik. (Korompis \& Latjandu, 2017). Audit judgement didukung oleh sikap independensi auditor (Fitria Alamri 2017). Independensi harus dimiliki oleh setiap auditor. Auditor independen akan leluasa membuat hasil laporan audit yang telah mereka lakukan tanpa mempertimbangkan hubungan atau kekeluargaan dengan kliennya (Vincent dan 
Osesoga, 2019). Namun auditor dengan kualitas yang baik terhadap teknologi, tidak dapat membenarkan independensinya (Pratama, Ahmad dan Maulida 2018).

\section{Kajian Teori dan Telaah Literatur}

Dalam menjalankan tugasnya, seorang auditor harus memiliki keahlian agar dapat dipercaya oleh perusahaan. Keahlian tersebut dapat diperoleh dari pengalaman, dimana auditor akan semakin mahir dalam membuat keputusan dalam menilai maupun memberi opini kepada banyak perusahaan. Artha, dkk (2014) mengatakan bahwa keahlian auditor disebut juga sebagai ilmu pengentahuan, pendidikan serta ketrampilan tinggi yang dimiliki oleh seorang auditor dan berasal darin pengalaman audit yang dimilikinya. Syafitri (2013) mengungkapan bahwa dalam menjalani tugasnya, seorang auditor harus memiliki keahlian sesuai dengan persyaratan keahlian auditor dan hal tersebut mampu terwujud jika auditor mengikuti pelatihan mengenai praktik akuntansi dan juga teknik pengauditan.

Selain keahlian, seorang auditor juga harus memiliki tingkat independensi yang tinggi. Menurut Yuliyana \& Waluyo (2018) independensi merupakan sikap tidak memihak yang harus dimiliki auditor dalam membuat opini atas informasi maupun fakta yang ditemukan dalam menjalankan tugasnya. Independensi merupakan sikap yang tidak mudah terpengaruhi dan dikendalikan oleh orang lain dan harus memiliki prinsip yang kuat dalam menjalankan tugasnya. Arens et al, (2012) mengungkapkan bahwa independensi terdiri dari 3 aspek yaitu independen dalam fakta, independen dalam penampilan dan juga independen dalam keahlian. Ketiga aspek tersebut harus dimiliki oleh seorang auditor dalam menjalankan tugasnya. Septriani (2012) mengatakan bahwa independensi menunjukkan adanya kejujuran auditor dalam mempertimbangkan fakta dengan tidak memihal dalam menyatakan opininya.

Audit Judgment merupakan pertimbangan atau pandangan yang dimiliki oleh seorang auditor dalam membuat opini atas informasi dan dokumentasi bukti serta membuat keputusan atas informasi yang ada. Limen dkk (2017) mengatakakan bahwa salah satu faktor pertimbangan yang dimiliki seorang auditor dalam menjalankan tugasnya adalah perilaku individu. Menurut Nugraha \& Januarti (2015) audit judgment merupakan suatu pertimbangan yang dimilili seorang auditor dalam menanggapi atas dokumentasi bukti yang akan berpengaruh terhadap pembuatan opini audit suatu perusahaan.

Berdasarkan dari latarbelakang dan teori telah diuraikan, maka penelitian ini memiliki tiga hipotesis yaitu:

$\mathbf{H}_{1}$ : Keahlian auditor berpengaruh positif terhadap audit judgment.

Penelitian sebelumnya yang dilakukan oleh Gracea, Kalangi (2017) menyatakan bahwa keahlian auditor berpengaruh signifikan terhadap audit judgment pada Perwakilan BPK RI Provinsi Sulawesi Utara. Hasil penelitian menunjukkan bahwa penilaian yang diambil oleh auditor akan semakin baik dan tepat jika keahlian yang dimiliki auditor semakin baik.

$\mathbf{H}_{2}$ : Independensi auditor berpengaruh positif terhadap audit judgment. 
Standar Profesional Akuntan Publik 2011 Pasal 220 menyatakan bahwa independensi tidak mementingkan keterikatan dengan pihak lain, bertindak jujur dengan pihak manapun, tidak mudah, menaruh kepercayaan pada pihak lain demi kepentingan laporan keuangan. Pernyataan ini didukung oleh penelitian yang dilakukan oleh Yuliani (2012) yang menyatakan bahwa auditor independen berpengaruh positif terhadap audit judgement. Analisis yang dilakukan oleh Ismunanwan dan Triyanto (2020), menyatakan bahwa independensi merupakan salah satu faktor yang mempengaruhi audit judgment.

$\mathbf{H}_{3}$ : Keahlian auditor dan independensi auditor secara simultan berpengaruh positif terhadap audit judgment.

Berdasarkan uraian teori dan hipotesis di atas, maka model kerangka pemikiran pada penelitian ini adalah sebagai berikut:

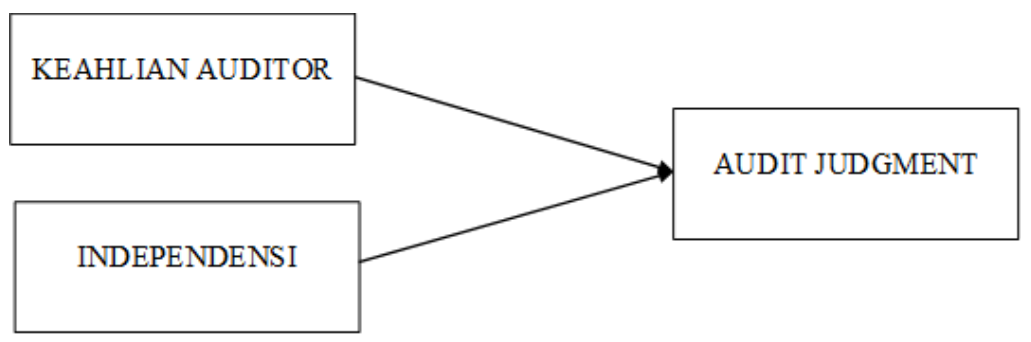

Gambar 1. Model Penelitian

\section{Metode Penelitian}

Dalam penelitian ini, penulis melakukan metode kualitatif dengan melakukan penyebaran kuesioner pada Kantor Akuntan Publik di DKI Jakarta. Dalam pengumpulan data, penulis melakukannya dengan cara form survey, dimana responden akan mengisi kuesioner yang ada pada form yang diberikan. Penulis melakukan uji instrumen dengan menguji reabilitas dan validitas dari kuesioner yang disebar. Dan peneliti perlu melakukan pengujian kembali atas uji validitas dan reliabilitasnya, mengingat adanya perbedaan waktu dan responden yang mengisi kuesioner tersebut.

Penelitian ini mengkaji dua variabel independen yaitu: keahlian auditor dan independensi auditor serta satu variabel dependen, yaitu: variabel dependen. Subjek penelitian dalam penelitian ini adalah auditor yang bekerja pada Kantor Akuntan Publik di Jakarta.

Table 1. Operasionalisasi Variabel

\begin{tabular}{|c|c|c|c|c|c|c|}
\hline No & Variabel & Tipe Variable & Indikator & & Skala & Item \\
\hline \multirow[t]{3}{*}{1.} & \multirow{3}{*}{$\begin{array}{l}\text { Audit } \\
\text { Judgment }\end{array}$} & \multirow[t]{3}{*}{ Dependen } & Materialitas & dengan & \multirow[t]{3}{*}{ Ordinal } & $1-2$ \\
\hline & & & $\begin{array}{l}\text { mempertimbangkan } \\
\text { tertentu }\end{array}$ & kondisi & & \multirow[t]{2}{*}{$3-4$} \\
\hline & & & $\begin{array}{l}\text { Kelangsungan Hidup } \\
\text { (Kelangsungan Hidup) } \\
\text { Tingkat Risiko Audit }\end{array}$ & Entitas & & \\
\hline \multirow[t]{2}{*}{2.} & Keahlian & \multirow[t]{2}{*}{ Independen } & \multirow{2}{*}{\multicolumn{2}{|c|}{$\begin{array}{l}\text { Komponen pengetahuan tentang } \\
\text { prinsip dan standar akuntansi }\end{array}$}} & Ordinal & $5-6$ \\
\hline & Auditor & & & & & $7-8$ \\
\hline
\end{tabular}




\begin{tabular}{|c|c|c|c|c|c|}
\hline \multirow{5}{*}{4.} & \multirow{5}{*}{$\begin{array}{l}\text { Independ } \\
\text { ensi }\end{array}$} & \multirow{5}{*}{ Independen } & $\begin{array}{l}\text { Bertanggung jawab dan mampu } \\
\text { berkomunikasi untuk kerjasama } \\
\text { Strategi pengambilan keputusan }\end{array}$ & & \\
\hline & & & Independensi Fakta & Ordinal & $12-13$ \\
\hline & & & Independensi Hubungan dengan & & $14-16$ \\
\hline & & & Klien & & $17-18$ \\
\hline & & & $\begin{array}{l}\text { Independensi Tekanan dengan } \\
\text { Klien }\end{array}$ & & \\
\hline
\end{tabular}

Penelitian ini menggunakan metode penelitian asosiatif hubungan kausal, yaitu hubungan kausal antara variabel bebas dan variabel terikat (Sugiyono, 2013). Auditor yang bekerja pada Kantor Akuntan Publik (KAP) di wilayah Jakarta menjadi responden dalam penelitian ini. Data primer yang digunakan dalam penelitian ini diperoleh dari kuisioner yang disebarkan langsung melalui google form kepada responden dari bulan Juli hingga Agustus 2020. Di tengah situasi pandemi, pendataan jenis ini lebih aman dan efisien. Setelah melewati jangka waktu yang ditentukan, seluruh kuesioner yang telah diisi mulai diolah.

Tabel 2 menunjukkan profil responden. Dapat disimpulkan bahwa sebagian besar responden berjenis kelamin laki-laki, yaitu sebanyak $56 \%$ dan perempuan $44 \%$. Untuk kelompok posisi responden pada posisi pertama adalah auditor senior sebesar $56 \%$ dan untuk auditor yunior $40 \%$. Untuk kategori lama bekerja menempati posisi terbanyak didominasi oleh responden yang bekerja 1-3 tahun sebanyak 44\%, kemudian bekerja dengan responden dengan lama kerja $<1$ tahun sebanyak $26 \%$.

Table 2. Profil Responden

\begin{tabular}{llll}
\hline Variabel & Klasifikasi & Responden & Persentase \\
\hline Jenis Kelamin & Perempuan & 22 & $44 \%$ \\
& Laki-laki & 28 & $56 \%$ \\
\hline Posisi & Junior Auditor & 20 & $40 \%$ \\
Respondent & Senior Auditor & 28 & $56 \%$ \\
& Asisten Manajer & 1 & $2 \%$ \\
& Manajer & 1 & $2 \%$ \\
\hline Lama bekerja & $<1$ tahun & 13 & $26 \%$ \\
& $1-3$ tahun & 22 & $44 \%$ \\
& $3-5$ tahun & 7 & $14 \%$ \\
& $5-10$ tahun & 6 & $12 \%$ \\
& $>10$ tahun & 2 & $4 \%$ \\
\hline
\end{tabular}

\section{Analisis Data}

Dalam penelitian ini digunakan analisis regresi linier berganda yang menguji satu variabel dependen dan dua variabel independen dengan model berikut:

Dimana:

$$
\mathrm{AJ}=\boldsymbol{\beta}_{0}+\boldsymbol{\beta}_{1} \mathrm{AE}+\boldsymbol{\beta}_{2} \mathrm{In}+\mathrm{e}
$$
AJ : : Audit Judgment
a : Konstan
$\beta \quad$ : Koefisien Regresi 


$$
\begin{array}{ll}
\text { AE } & \text { : Keahlian Auditor } \\
\text { In } & \text { : Independensi } \\
\text { e } & \text { : error (5\%) dan signifikan (95\%) }
\end{array}
$$

\section{Hasil dan Pembahasan}

Penelitian ini menggunakan uji validitas dan reliabilitas untuk menguji kualitas data. Hasil uji validitas menunjukan semua indikator penelitian ini dinyatakan valid. Tabel 3 menunjukkan bahwa masing-masing variabel memiliki nilai Pearson Correlation >0,30.

Table 3 Uji Validitas

\begin{tabular}{llll}
\hline Variabel & $\begin{array}{l}\text { Kode } \\
\text { Instrumen }\end{array}$ & $\begin{array}{l}\text { Nilai } \\
\text { Pearson } \\
\text { Correlation }\end{array}$ & Informasi \\
\hline Keahlian & X1.1 & 0,534 & valid \\
Auditor & X1.2 & 0,670 & valid \\
& X1.3 & 0,614 & valid \\
& X1.4 & 0,666 & valid \\
& X1.5 & 0,761 & valid \\
\hline Independensi & X2.1 & 0,572 & valid \\
& X2.2 & 0,309 & valid \\
& X2.3 & 0,531 & valid \\
& X2.4 & 0,619 & valid \\
& X2.5 & 0,686 & valid \\
& X2.6 & 0,675 & valid \\
& X2.7 & 0,592 & valid \\
& X2.8 & 0,776 & valid \\
\hline Audit & Y1.1 & 0,538 & valid \\
Judgment & Y1.2 & 0,745 & valid \\
& Y1.3 & 0,497 & valid \\
& Y1.4 & 0,692 & valid \\
& Y1.5 & 0,814 & valid \\
\hline
\end{tabular}

Table 4. Uji Reliabilitas

\begin{tabular}{lll}
\hline Variable & Cronbach's Alpha & Information \\
\hline Keahlian Auditor $(X 1)$ & 0.649 & Reliable \\
Independensi $(X 3)$ & 0,641 & Reliable \\
Audit Judgment $(Y)$ & 0,420 & Reliable \\
\hline
\end{tabular}

Hasil uji reliabilitis harus memenuhi kriteria Cronbach Alpha> 0,60. Tabel 4 menunjukkan Cronbach's Alpha dari masing-masing variable, yaitu: keahlian auditor $=0,649$, independensi $=0,641$ dan audit judgment $=0,709$, sehingga kuesioner dalam penelitian ini reliabel dan dapat digunakan. 


\section{Analisis Regresi Linear Berganda}

Uji-t dilakukan untuk menentukan pengaruh dari masing-masing variabel independen terhadap audit judgment. Tabel 5 menunjukkan hasil uji-t. Tabel 5 menunjukkan bahwa hipotesis 1 diterima, keahlian auditor berpengaruh positif terhadap audit judgment dengan tingkat signifikansi 0,040 < 0,05 dan hipotesis 1 diterima, independensi auditor berpengaruh positif terhadap judgement audit dengan signifikansi $0,008<0,05$.

Tabel. 5 Hasil Uji-t

\begin{tabular}{|c|c|c|c|c|c|c|}
\hline \multirow[b]{2}{*}{ Madel } & & \multicolumn{2}{|c|}{ Unstandardized Coefficients } & \multirow{2}{*}{$\begin{array}{c}\begin{array}{c}\text { Standardized } \\
\text { Coefficients }\end{array} \\
\text { Beta } \\
\end{array}$} & \multirow[b]{2}{*}{$t$} & \multirow[b]{2}{*}{ Siq. } \\
\hline & & $\mathrm{B}$ & Std. Error & & & \\
\hline 1 & (Constant) & 6.927 & 3.387 & & 2.045 & .046 \\
\hline & Auditor Expertise ( $(1)$ & .313 & .148 & .283 & 2.113 & .040 \\
\hline & Independence $(\alpha 2)$ & .278 & .099 & .375 & 2.792 & .008 \\
\hline
\end{tabular}

a. Dependent Variable: Audit Judgement $(n)$

Koefisien regresi keahlian auditor adalah 0,313 yang menunjukkan semakin tinggi keahlian auditor akan memberikan audit judgement yang lebih baik. Artinya keahlian auditor berpengaruh positif terhadap audit judgment. Artinya keahlian auditor telah sesuai dengan audit judgment. Ketika keahlian auditor meningkat, skor audit judgement akan meningkat sebesar 0,313 . Koefisien regresi independensi auditor sebesar 0,278 yang berarti semakin tinggi independensi maka semakin baik audit judgment. Artinya independensi berpengaruh positif terhadap audit judgment. Artinya independensi sejalan dengan audit judgment. Ketika independensi meningkat, audit judgement akan meningkat sebesar 0,278.

Penelitian ini menggunakan uji-F untuk menentukan pengaruh kedua variabel independen terhadap audit judgment. Tabel 6 menunjukkan hasil uji-F, bahwa bahwa hipotesis 3 diterima, bahwa secara simultan keahlian auditor dan independensi auditor berpengaruh signifikan positif terhadap audit judgment dengan tingkat signifikansi $0,000<0,05$.

Tabel. 6 ANOVA

\begin{tabular}{|c|c|c|c|c|c|c|}
\hline \multicolumn{7}{|c|}{ ANOWA ${ }^{b}$} \\
\hline \multicolumn{2}{|c|}{ Model } & $\begin{array}{l}\text { Sum of } \\
\text { Squares }\end{array}$ & df & Mean Square & $\mathrm{F}$ & Sig. \\
\hline \multirow[t]{3}{*}{1} & Regression & 115.132 & 2 & \multirow{3}{*}{$\begin{array}{r}57.566 \\
5.391\end{array}$} & \multirow[t]{3}{*}{10.679} & \multirow[t]{3}{*}{$.000^{2}$} \\
\hline & Residual & 253.368 & 47 & & & \\
\hline & Total & 368.500 & 49 & & & \\
\hline \multicolumn{7}{|c|}{ a. Predictors: (Constant), Independence $(\times 2)$, Auditor Expertise $(\times 1)$} \\
\hline \multicolumn{7}{|c|}{ b. Dependent Variable: Audit Judgement ( $)$} \\
\hline
\end{tabular}


Tabel. 7 Koefisien Determinasi

\begin{tabular}{|c|c|c|c|c|}
\hline Mode & $\mathrm{R}$ & R Square & $\begin{array}{c}\text { Adjusted R } \\
\text { Square }\end{array}$ & $\begin{array}{l}\text { Std. Error of } \\
\text { the Estimate }\end{array}$ \\
\hline 1 & $.559=$ & .312 & .283 & 2.32181 \\
\hline
\end{tabular}

Tabel 7 menunjukkan bahwa keahlian auditor dan independensi auditor berpengaruh positif signifikan terhadap audit judgment dan dapat menjelaskan audit judgment 55,9\%, sedangkan sisanya $44,1 \%$ dijelaskan oleh variabel lain yang tidak dijelaskan dalam penelitian ini, Dalam mengaudit laporan keuangan untuk mendapatkan hasil yang akurat, seorang auditor harus dapat meningkatkan keahlian dan independensinya serta mengurangi tekanan.

\section{Penutup dan Saran}

Berdasarkan hasil penelitian dari judul "Pengaruh Keahlian Auditor dan Independensi Auditor terhadap Audit Judgment", maka diambil kesimpulan keahlian auditor berpengaruh positif terhadap audit judgment. Dapat disimpulkan bahwa variabel keahlian auditor berpengaruh positif signifikan terhadap audit judgment. Artinya, semakin tinggi keahlian auditor, semakin akurat audit judgement. Keahlian auditor sangat didukung oleh pendidikan dan pengalaman. Penelitian ini didukung oleh Nirmala dan Latrini (2017) yang menyatakan bahwa penilaian yang dihasilkan akan semakin baik dan akurat jika keahlian yang dimiliki oleh seorang auditor semakin tinggi. Kemudian Priyoga dan Ayem (2019), keahlian audit berhubungan positif dengan audit judgment. Independensi berpengaruh positif terhadap audit judgement, semakin tinggi karakter independensi seorang auditor maka semakin akurat dan tepat hasil auditnya. Oleh karena itu auditor independen adalah auditor yang tidak memperhatikan sifat kekerabatan atau kekerabatan dengan klien.Keahlian auditor dan independensi auditor secara simultan berpengaruh positif terhadap audit judgment sebesar $55,9 \%$ dan sisanya dijelaskan oleh variabel lain di luar model yang telah ditentukan.

Saran yang dapat diambil dari penelitian ini adalah ketika seorang auditor ingin membuat laporan keuangan yang akurat dan akurat, auditor harus meningkatkan keahliannya dengan belajar menambah pengalamannya. Meningkatkan kemandirian auditor tanpa memandang kekerabatan dengan klien. Saran bagi KAP adalah memberikan banyak pelatihan dan menambah pengalaman auditor. Dengan demikian, keahlian auditor akan meningkat dan audit judgement. yang dihasilkan akan lebih tepat dan akurat. Selain itu, setiap auditor di KAP memiliki karakteristik independensi yang kuat. Dan diharapkan tekanan pada auditor dapat diminimalkan.

\section{Referensi}

Agustini, N. K. R., \& Merkusiwati, N. K. L. A. (2016). Pengaruh Tekanan Ketaatan, Senioritas Auditor, dan Tekanan Anggaran Waktu Terhadap Audit Judgment. E-Jurnal Akuntansi Universitas Udayana, 15(1), 433-462.

Alamri, F., Nangoi, G. B., \& Tinangon, J. (2017). Pengaruh Keahlian, Pengalaman, Kompleksitas Tugas Dan Independensi Terhadap Audit Judgement Auditor Internal 
Pada Inspektorat Provinsi Gorontalo. Jurnal EMBA: Jurnal Riset Ekonomi, Manajemen, Bisnis dan Akuntansi, 5(2), 593-601.

Andryani, H., Piturungsih, E., \& Furkan, L. M. (2019). Pengaruh Tekanan Ketaatan, Keahlian Audit dan Pengalaman Audit Terhadap Audit Judgment dengan Kompleksitas Tugas Sebagai Pemoderasi. Jurnal Riset Akuntansi Aksioma, 18(2), 79-115.

Arens, A. A., Elder, R. J., \& Mark, B. (2012). Auditing And Assurance Services: An Integrated Approach. Boston: Prentice Hall.

Ariyantini, K. E., Edy Sujana, S. E., Darmawan, N. A. S., \& SE, A. (2014). Pengaruh Pengalaman Auditor, Tekanan Ketaatan, Dan Kompleksitas Tugas Terhadap Audit Judgment (Studi Empiris Pada BPKP Perwakilan Provinsi Bali). JIMAT (Jurnal Ilmiah Mahasiswa Akuntansi) Undiksha, 2(1), 1-10.

Artha, I. M. A. P., Herawati, N. T., AK, S., Darmawan, N. A. S., \& SE, A. (2014). Pengaruh keahlian audit, konflik peran dan kompleksitas tugas terhadap audit judgment (studi kasus pada inspektorat pemerintah Kabupaten Gianyar dan Kabupaten Bangli). JIMAT (Jurnal Ilmiah Mahasiswa Akuntansi) Undiksha, 2(1), 1-12.

Azizah, N., Kustono, A. S., \& Fitriya, E. (2019). Pengaruh Kompetensi Audit, Kompleksitas Tugas dan Locus of Control Terhadap Audit Judgment. Jurnal Ilmu Sosial dan Humaniora, 8(1), 46-51.

Gracea, A., Kalangi, L., \& Rondonuwu, S. (2017). Pengaruh Keahlian Auditor, Pengetahuan Auditor Dan Kompleksitas Tugas Terhadap Audit Judgment (Studi Kasus Pada BPK RI Perwakilan Provinsi Sulawesi Utara). Jurnal EMBA: Jurnal Riset Ekonomi, Manajemen, Bisnis dan Akuntansi, 5(2)., 2627-2636.

Haryanto, H. (2012). Debiasing Audit Judgment: Akuntabilitas dan Tipe Pembuat Keputusan. Jurnal Ilmiah Akuntansi dan Humanika, 2(1), 1-25.

Hasanah, N., \& Rosini, I. (2016). Determinan Audit Judgment: Studi Pada Kantor Akuntan Publik di Jakarta Selatan. Akuntabilitas, 9(2), 185-194.

Ismunawan, I., \& Triyanto, E. (2020). Faktor-Faktor Penentu Audit Judgement Pada Kantor Akuntan Publik (Kap Di Surakarta Dan Yogyakarta). Jurnal Akuntansi dan Pajak, 20(2), 224-229.

Komalasari, R., \& Hernawati, E. (2015). Pengaruh Independensi, Kompleksitas Tugas, dan Gender terhadap Audit Judgment. Neo-Bis, 9(2), 66-86.

Korompis, C. W. M., \& Latjandu, L. D. (2017). Pengaruh Narsisme Klien, Audit Fee, Independensi, Skeptisme Profesional, Dan Interlock Auditor Eksternal Terhadap Audit Judgement Dalam Pendeteksian Kecurangan Laporan Keuangan (Studi Kasus Pada Kap Di Manado). Going Concern: Jurnal Riset Akuntansi, 12(2), 594-604.

Limen, M. M. P., Karamoy, H., \& Gamaliel, H. (2017). Analisis Faktor-Faktor yang Mempengaruhi Audit Judgment pada Auditor. Going Concern: Jurnal Riset Akuntansi, 12(2), 224-230. 
Mulyadi. (2013). Sistem Akuntansi (Edisi Ketiga, Volume Keempat ed.). Jakarta.

Munawaroh, S. (2019). Pengaruh Independensi dan Motivasi Terhadap Kualitas Audit pada Kantor Inspektorat Kabupaten Berau. JEMMA | Journal of Economic, Management and Accounting, 2(1), 27-35.

Nirmala, M. R. V., \& Latrini, M. Y. (2017). Pengaruh Keahlian, Tekanan Ketaatan, Tekanan Waktu Terhadap Kualitas Audit Judgment Dengan Kompleksitas Tugas Sebagai Pemoderasi. E-Jurnal Akuntansi, 19(1), 683-711.

Noor, I. N., Pujianthi, E., \& Hamun, M. (2019). Effect of Audit Expertise, Compliance Pressure, Task Complexity, and Experience on Audit Judgement. Mega Aktiva: Jurnal Ekonomi dan Manajemen, 8(2), 100-112.

Nugraha, A. P., \& Januarti, H. I. (2015). Pengaruh Gender, Pengalaman, Keahlian Auditor dan Tekanan Ketaatan terhadap Auditor Judgment dengan Kompleksitas Tugas sebagai Variabel Moderasi pada BPK RI Jawa Tengah. Diponegoro Journal of Accounting, 4(4), $1-11$.

Nurfadillah, N., \& Nurhuda, N. (2020). Pengaruh Due Professional Care dan Akuntabilitas Auditor terhadap Kualitas Audit. JEMMA| Journal of Economic, Management and Accounting, 3(1), 1-13.

Pektra, S., \& Kurnia, R. (2015). Pengaruh Gender, Kompleksitas Tugas, Tekanan Ketaatan, Pengalaman Auditor Terhadap Audit Judgement. Ultimaccounting: Jurnal Ilmu Akuntansi, 7(1), 1-20.

Pratama, B. C., Ahmad, Z. A., \& Innayah, M. N. (2019). Obedience Pressure, Professional Ethics, Attitude of Skepticism and Independency Towards Audit Judgment. Journal of Accounting Science, 2(2), 141-149.

Priyoga, I., \& Ayem, S. (2019). Pengaruh Tekanan Ketaatan, Gender, Kompleksitas Tugas, Independensi, dan Pengalaman Auditor Terhadap Audit Judgment. Kajian Bisnis Sekolah Tinggi Ilmu Ekonomi Widya Wiwaha, 27(1), 61-72.

Putra, A. M. T., \& Rani, P. (2016). Pengaruh Gender, Kompleksitas Tugas, Pengalaman Auditor dan Kompetensi Profesional Terhadap Audit Judgement (Studi Empiris Pada Auditor Kantor Akuntan Publik Di Wilayah DKI Jakarta dan Tangerang Periode 2016). Jurnal Akuntansi dan Keuangan, 5(2), 80-100.

Putri, P. A., \& Laksito, H. (2013). Pengaruh lingkungan etika, pengalaman auditor dan tekanan ketaatan terhadap kualitas audit judgment. Diponegoro Journal of Accounting, 383-393.

Rosadi, R. A., \& Waluyo, I. (2017). Pengaruh Gender, Tekanan Ketaatan, Tekanan Anggaran Waktu dan Pengalaman Audit terhadap Audit Judgment. Nominal: Barometer Riset Akuntansi dan Manajemen, 6(1), 124-135.

Septriani, Y. (2012). Pengaruh Independensi Dan Kompetensi Auditor Terhadap Kualitas Audit, Studi Kasus Auditor Kap Di Sumatera Barat. Jurnal Akuntansi $\mathcal{E}$ Manajemen, 7(2), 78-100. 
Sitanggang, T. (2020). The Influence of an Auditor's Expertise, Obedience Pressure, and Independence on Audit Judgment. International Journal of Contemporary Accounting, 2(1), 1-16.

Tampubolon, L. (2018). Pengaruh Tekanan Ketaatan, Pengetahuan, Dan Pengalaman Auditor Terhadap Audit Judgment. InFestasi (Jurnal Bisnis dan Akuntansi), 14(2), 169-177.

Tibe, H., \& Dewi, N. N. S. R. T. (2019). Pengaruh Kompleksitas Tugas, Pengalaman Auditor, Skeptisme dan Tekanan Anggaran Waktu Terhadap Audit Judgment. Journal Research of Accounting (JARAC), 1(1), 45-62.

Vincent, N., \& Osesoga, M. S. (2019). Pengaruh Pengalaman Auditor, Keahlian Auditor, Independensi, Tekanan Ketaatan, dan Kompleksitas Tugas terhadap Audit Judgement. Ultimaccounting: Jurnal Ilmu Akuntansi, 11(1), 58-80.

Yendrawati, R., \& Mukti, D. K. (2015). Pengaruh gender, pengalaman auditor, kompleksitas tugas, tekanan ketaatan, kemampuan kerja dan pengetahuan auditor terhadap audit judgement. Asian Journal of Innovation and Entrepreneurship, 4(1), 1-8.

Yuliani, N. L. (2012). Tekanan Ketaatan, Kompleksitas Tugas, Independensi, Pengetahuan, dan Pengalaman Auditor Terhadap Audit Judgment. Jurnal Analisis Bisnis Ekonomi, 10(1), 40-53.

Yuliyana, S., \& Waluyo, I. (2018). Pengaruh Framing dan Independensi Auditor terhadap Audit Judgment. Nominal: Barometer Riset Akuntansi dan Manajemen, 7(2), 33-46. 